\title{
Canadian Association of Gastroenterology position statement regarding the use of thiopurines for the treatment of inflammatory bowel disease
}

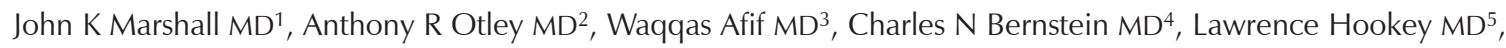 \\ Grigorios Leontiadis $M D^{1}$, Remo Panaccione $M^{6}{ }^{6}$, Brian Bressler $M^{7}$
}

$T^{h}$ he Canadian Association of Gastroenterology is issuing the 1 present position statement to address concerns resulting from the recent Health Canada warning, "Imuran (azathioprine) or Purinethol (mercaptopurine) - association with a type of blood cancer - hepatosplenic T-cell lymphoma - for health professionals" (Box 1) (1). While the alert does not contain new information, it informs clinicians of updates to the product labelling for azathioprine (Imuran, Triton Pharma Inc, Canada) and 6-mercaptopurine (Purinethol, Teva Canada Ltd, Canada) to include the association with the development of hepatosplenic T cell lymphoma (HSTCL). This serious cancer has been rare in Canada, with Health Canada reports including two cases (one fatal) with mercaptopurine and four cases with azathioprine (three fatal).

Although these agents are not Health Canada-approved for inflammatory bowel disease (IBD), they are frequently administered 'off-label' for the treatment of ulcerative colitis (UC) and Crohn disease (CD). Many therapies are used off-label, particularly in pediatric patients $(2,3)$. Other common therapies included in IBD management guidelines, such as corticosteroids (prednisone) and methotrexate, are similarly not authorized for this indication. This does not imply improper or contraindicated use, but rather that clinicians use their professional judgment and the best available evidence to weigh the risk:benefit ratio for an individual patient (3).

The efficacy of thiopurine therapy in IBD is somewhat controversial. The Study of Immunomodulator Naive Patients in Crohn's Disease (SONIC) (4) and UC SUCCESS (5) trials demonstrated that azathioprine in combination with an anti-tumour necrosis factor-alpha (TNF- $\alpha$ ) agent was superior to either agent alone in CD and UC for induction and maintenance therapy. These same studies suggest that azathioprine monotherapy is an inferior choice for induction and maintenance therapy in both UC and CD $(4,5)$. Furthermore, recent studies have questioned the benefits of introducing thiopurines early in the disease course $(6,7)$. However, in other trials, thiopurine agents have demonstrated benefits for steroid sparing and maintenance of remission (8-10). As a result, recent European and United States guidelines recommend thiopurines with or without anti-TNFs to maintain remission after failure of, or intolerance to, 5-aminosalicylic acid compounds (8-10).

Efficacy must be balanced against safety and tolerability. Immunosuppression can be associated with an increased risk for cancer. Specifically, thiopurines are associated with a small but significant risk of lymphoma (including HSTCL) $(8,11)$ and nonmelanoma skin cancer (12). Although there is an increased relative risk for lymphoma with thiopurine therapy in IBD patients, the absolute risk is very low (11). Of note, some subgroups, such as elderly patients, may face a much higher absolute risk of thiopurine complications because of a higher baseline risk (13). Thiopurines are also associated with bone

\section{BOX 1}

Health Canada warning of association of hepatosplenic T cell lymphoma with thiopurine therapy (1)

- Cases of hepatosplenic T cell lymphoma (including fatalities) have been reported in inflammatory bowel disease patients treated with azathioprine (Imuran, Triton Pharma Inc, Canada) or 6-mercaptopurine (Purinethol, Teva Canada Ltd, Canada) monotherapy

- Imuran and Purinethol labels have been updated for hepatosplenic T cell lymphoma and physicians should discuss the currently available information regarding risks and benefits of these treatments with their patients

- Imuran or Purinethol monotherapies are not authorized by Health Canada for the treatment of inflammatory bowel disease

marrow suppression, hepatotoxicity, pancreatitis, allergic reactions and an increased risk for opportunistic infections, especially when used concomitantly with steroids or infliximab $(8,9)$.

The risks associated with thiopurine use, including those highlighted in the Health Canada alert, have been known to clinicians for some time and should be considered in their decision-making process. It is important to discuss both the risks and benefits of thiopurine therapy with patients to avoid uninformed decisions and abrupt discontinuation of therapy. Patients should be cautioned that treatment withdrawal among patients in stable remission on azathioprine has been associated with an increased risk for relapse (14).

Clinicians should conduct routine discussions to ensure that patients are aware of the balance of risk and benefits of therapies as a standard part of care (15). This most recent Health Canada warning reinforces our responsibility to stay current with regard to the risk and benefits of the medications we prescribe. Taking this one step further, it is our duty to communicate these points to our patients. Some suggestions for effective communications to help patients make informed medical decisions include avoiding vague descriptive words (eg, rare, common), using multiple formats (eg, numbers, graphs, pictorial representations), using absolute as opposed to relative numbers, avoiding small percentages (eg, $0.06 \%$, use 6 per 10,000 instead) and individualizing data whenever possible (15).

Management decisions should be individualized. Continuation of therapy should balance the evidence for risk and efficacy against an individual patient's response to therapy, preferences and risk tolerance. Some patients may have a higher risk tolerance than clinicians would predict (16). Therefore, it is important to have an open, individualized discussion and document this in the patient's chart. Although events are relatively rare, clinicians must continue to be aware of the risk and counsel patients appropriately.

${ }^{1}$ Division of Gastroenterology and Farncombe Family Digestive Health Research Institute, McMaster University, Hamilton, Ontario; ${ }^{2}$ Division of Gastroenterology $\mathcal{E}$ Nutrition, Dalhousie University, Halifax, Nova Scotia; ${ }^{3}$ Division of Gastroenterology, McGill University, Montreal, Quebec;

${ }^{4}$ Section of Gastroenterology, University of Manitoba, Winnipeg, Manitoba; 5 Division of Gastroenterology, Queen's University, Kingston, Ontario;

${ }^{6}$ Division of Gastroenterology, University of Calgary, Calgary, Alberta; ${ }^{7}$ Division of Gastroenterology, University of British Columbia, Vancouver, British Columbia

Correspondence: Dr John K Marshall, Division of Gastroenterology, McMaster University, 1280 Main Street West (2F59), Hamilton, Ontario L8S 4K1.

Telephone 905-521-2100 ext 76782, fax 905-523-6048, e-mail marshllj@mcmaster.ca

Received for publication June 4, 2014. Accepted June 9, 2014 
ACKNOWLEDGEMENT: The authors thank Ms Pauline Lavigne for her assistance in preparing the manuscript.

\section{REFERENCES}

1. Health Canada. Imuran (azathioprine) or Purinethol (mercaptopurine) - association with a type of blood cancer hepatosplenic T-cell lymphoma - for health professionals. $<$ http://healthycanadians.gc.ca/recall-alert-rappel-avis/ hc-sc/2014/38691a-eng.php> (Accessed May 17, 2014).

2. Rieder MJ. Drug research and treatment for children in Canada: A challenge. Paediatr Child Health 2011;16:560-1.

3. Frattarelli DA, Galinkin JL, Green TP, et al. Off-label use of drugs in children. Pediatrics 2014;133:563-7.

4. Colombel JF, Sandborn WJ, Reinisch W, et al. Infliximab, azathioprine, or combination therapy for Crohn's disease. N Engl J Med 2010;362:1383-95.

5. Panaccione R, Ghosh S, Middleton S, et al. Combination therapy with infliximab and azathioprine is superior to monotherapy with either agent in ulcerative colitis. Gastroenterology 2014;146:392-400.

6. Cosnes J, Bourrier A, Laharie D, et al. Early administration of azathioprine vs conventional management of Crohn's disease: A randomized controlled trial. Gastroenterology 2013;145:758-65.

7. Panes J, Lopez-Sanroman A, Bermejo F, et al. Early azathioprine therapy is no more effective than placebo for newly diagnosed Crohn's disease. Gastroenterology 2013;145:766-74.

8. Kornbluth A, Sachar DB. Ulcerative colitis practice guidelines in adults: American College of Gastroenterology, Practice Parameters Committee. Am J Gastroenterol 2010;105:501-23; quiz 24.
9. Dignass A, Lindsay JO, Sturm A, et al. Second European evidencebased consensus on the diagnosis and management of ulcerative colitis part 2: Current management. J Crohns Colitis 2012;6:991-1030.

10. Dignass A, Van Assche G, Lindsay JO, et al. The second European evidence-based consensus on the diagnosis and management of Crohn's disease: Current management. J Crohns Colitis 2010;4:28-62.

11. Smith MA, Irving PM, Marinaki AM, Sanderson JD. Review article: Malignancy on thiopurine treatment with special reference to inflammatory bowel disease. Aliment Pharmacol Ther 2010;32:119-30.

12. Ariyaratnam J, Subramanian V. Association between thiopurine use and nonmelanoma skin cancers in patients with inflammatory bowel disease: A meta-analysis. Am J Gastroenterol 2014;109:163-9.

13. Beaugerie L, Brousse N, Bouvier AM, et al. Lymphoproliferative disorders in patients receiving thiopurines for inflammatory bowel disease: A prospective observational cohort study. Lancet 2009;374:1617-25.

14. Lemann M, Mary JY, Colombel JF, et al. A randomized, doubleblind, controlled withdrawal trial in Crohn's disease patients in long-term remission on azathioprine. Gastroenterology 2005;128:1812-8.

15. Siegel CA. Review article: Explaining risks of inflammatory bowel disease therapy to patients. Aliment Pharmacol Ther 2011;33:23-32.

16. Johnson FR, Hauber B, Ozdemir S, et al. Are gastroenterologists less tolerant of treatment risks than patients? Benefit-risk preferences in Crohn's disease management. J Manag Care Pharm 2010;16:616-28. 


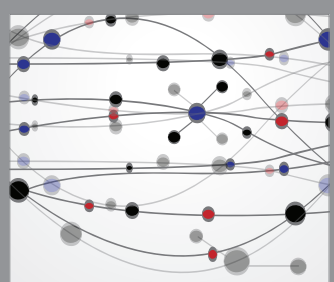

The Scientific World Journal
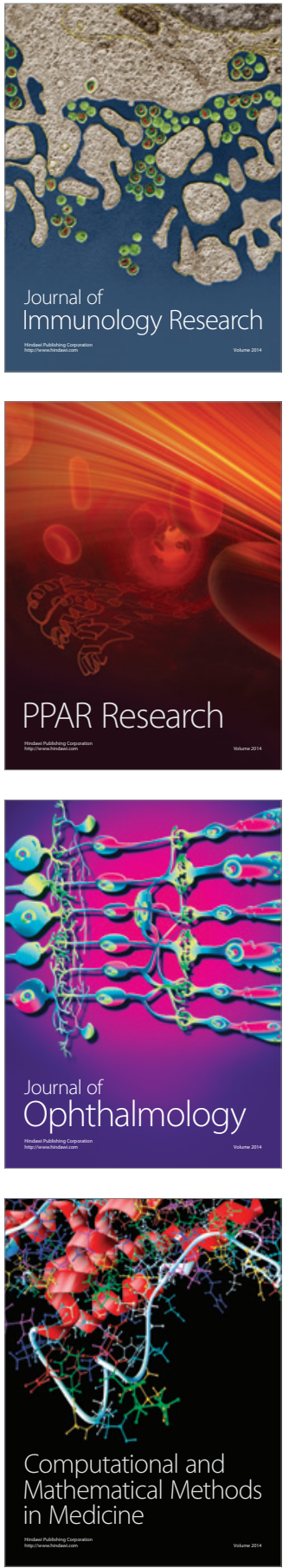

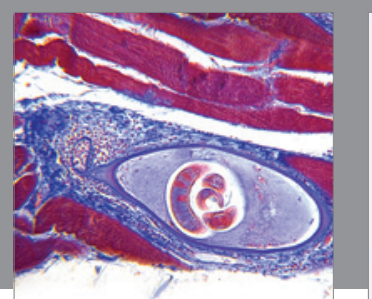

Gastroenterology Research and Practice

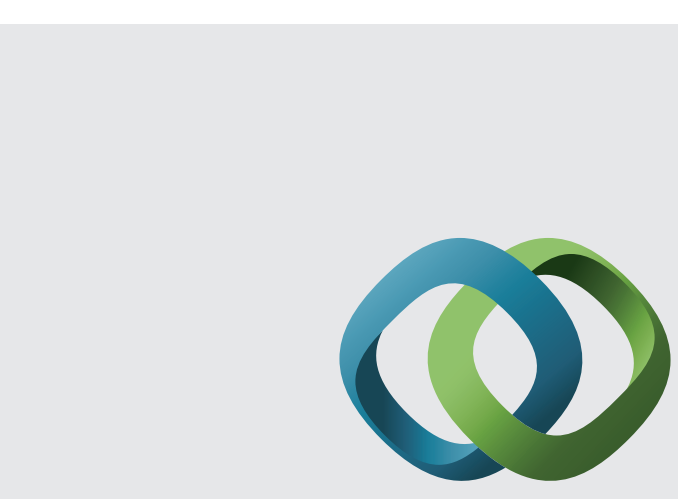

\section{Hindawi}

Submit your manuscripts at

http://www.hindawi.com
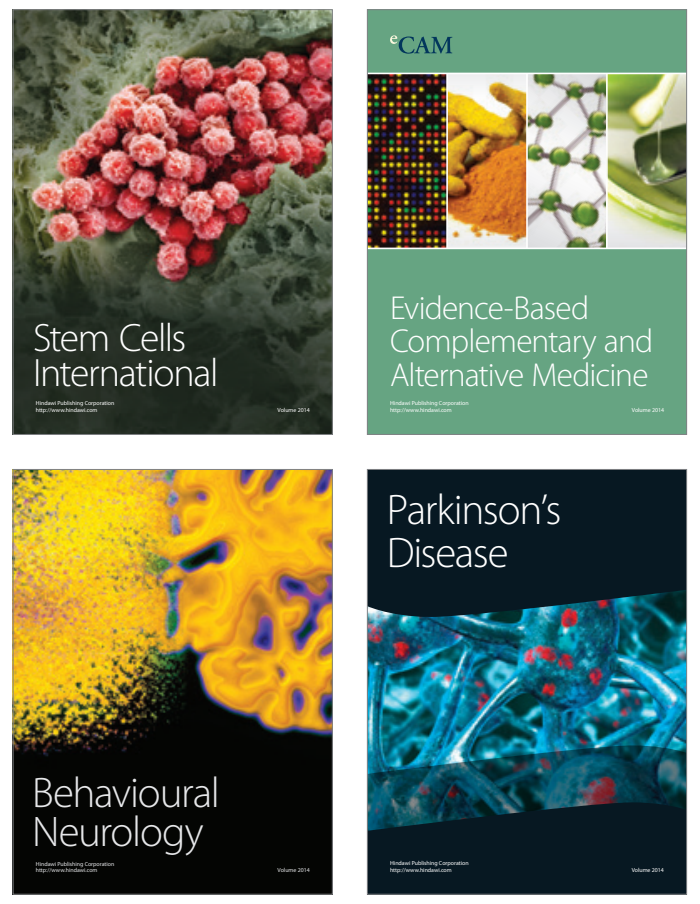
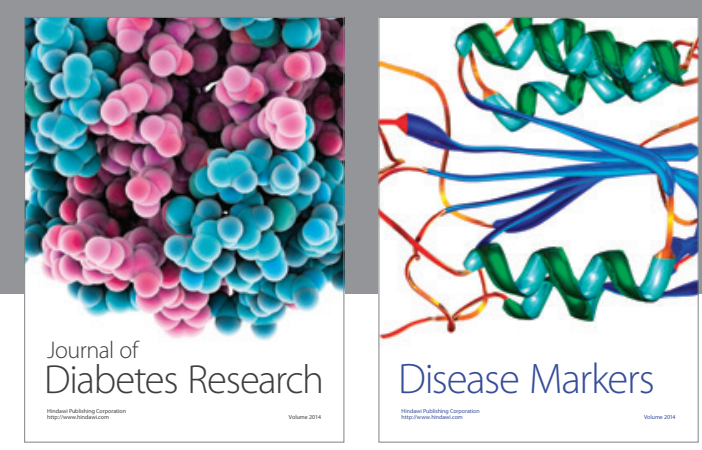

Disease Markers
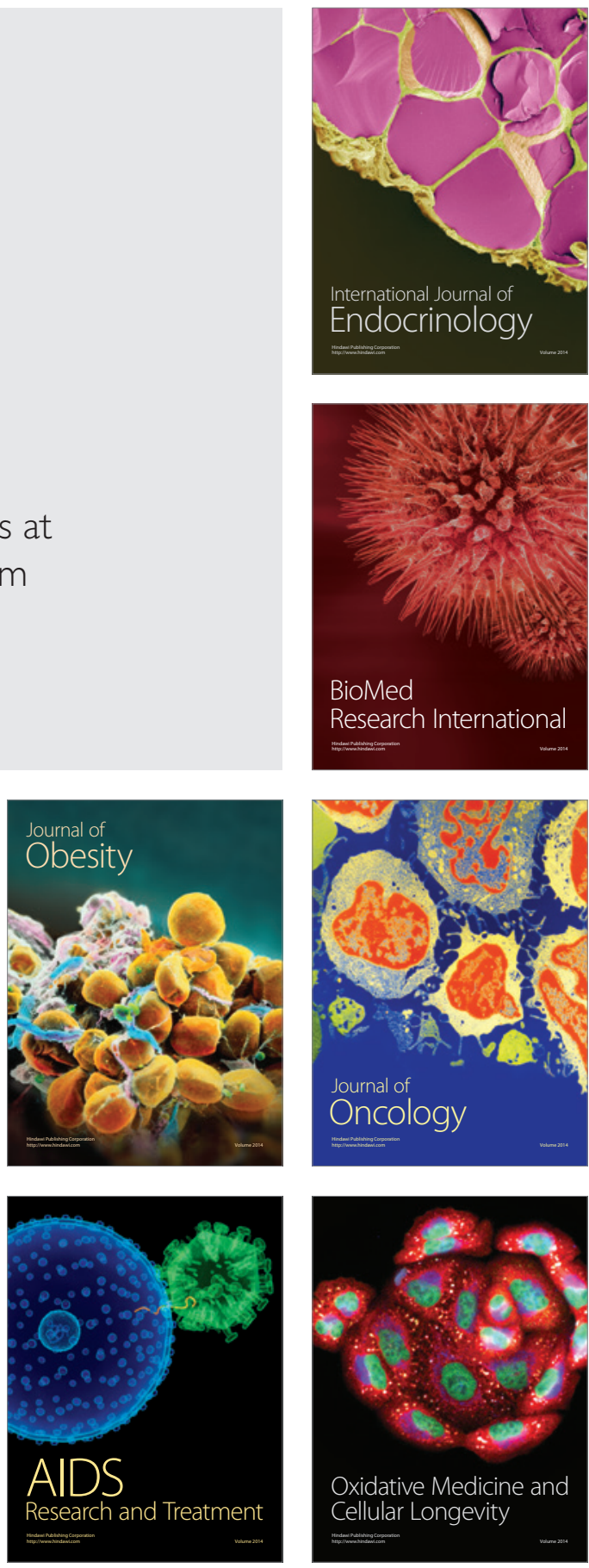